\title{
Effects of Co-exposure to Noise and Mixture of Organic Solvents on Blood Pressure
}

\author{
Ta-Yuan $\mathrm{CHANG}^{1}$, Ven-Shing $\mathrm{WANG}^{1}$, Bing-Fang Hwang ${ }^{1}$, Hsin-Yu YeN ${ }^{1}$, Jim-Shoung LaI ${ }^{1}$, \\ Chiu-Shong LIU ${ }^{2}$ and Shou-Yu LIN ${ }^{3}$
}

${ }^{1}$ Department of Occupational Safety and Health, College of Public Health, China Medical University, ${ }^{2}$ Department of Family Medicine, China Medical University Hospital and ${ }^{3}$ Institute of Environmental Health, College of Public Health, China Medical University, Taiwan, ROC

\begin{abstract}
Effects of Co-exposure to Noise and Mixture of Organic Solvents on Blood Pressure: Ta-Yuan ChANG, et al. Department of Occupational Safety and Health, College of Public Health, China Medical University, Taiwan, ROC-Objectives: Independent exposure to noise or organic solvents is reported to be associated with cardiovascular effects, but the effect of joint exposure is unclear. The present study aimed to investigate effects of noise, a mixture of organic solvents (N,N-dimethylformamide (DMF) and toluene) and their interaction on hypertension. Methods: We recruited 59 volunteers working in a synthetic leather manufacturing company during 20052006. Both personal noise exposure and airborne coexposure to DMF and toluene at work were measured and used to calculate the mixed hazard index $(\mathrm{HI})$. Multivariate logistic regressions were conducted to estimate between-group differences of hypertension by controlling for potential confounders. Results: We found that 18 co-exposure workers $(82.22 \pm 2.70 \mathrm{dBA}$ and a mixed $\mathrm{HI}$ of $0.53 \pm 0.20$ ) had the highest prevalence of hypertension (55.6\%) compared to 15 solvent-exposure workers (a mixed $\mathrm{HI}$ of $0.32 \pm 0.18$; $46.7 \%), 9$ noise-exposure workers $(84.13 \pm 2.30 \mathrm{dBA}$; $44.4 \%)$ and 17 low-exposure workers $(11.8 \%)$. The adjusted odds ratio (OR) of hypertension compared to low-exposure workers increased from 7.9 times $(95 \%$ confidence interval $(\mathrm{Cl})=0.9-66.3 ; p=0.06)$ in solventexposure workers and 9.1 times $(\mathrm{OR}=9.1,95 \% \mathrm{Cl}=1.0$ $81.1 ; p<0.05)$ in noise-exposure workers to 13.5 times $(95 \% \mathrm{Cl}=1.5-117.8 ; p<0.05)$ in co-exposure workers. Conclusions: Our findings suggest that co-exposure
\end{abstract}

Received Aug 22, 2008; Accepted Apr 23, 2009

Published online in J-STAGE Jun 8, 2009

Correspondence to: T.-Y. Chang, Department of Occupational Safety and Health, College of Public Health, China Medical University, 91 Hsueh-Shih Road, Taichung 40402, Taiwan, ROC (e-mail: tychang@mail.cmu.edu.tw.) to noise, DMF and toluene is associated with hypertension in synthetic leather workers. Simultaneous exposure to noise and a mixture of organic solvents may have a sub-additive effect on the risk of hypertension.

(J Occup Health 2009; 51: 332-339)

Key words: Hypertension, N,N-dimethylformamide, Noise, Occupational exposure, Toluene

Simultaneous exposure to noise and a mixture of organic solvents is often observed in certain industries and understanding the possible effects of combined exposure is vital. Many epidemiologic studies have reported that co-exposure to noise and organic solvents is associated with hearing loss ${ }^{1-4}$. This association may be because exposure to either noise or a mixture of organic solvents damages the auditory function. Several field studies have revealed that the risk of hearing loss is greater for groups exposed to noise and solvent mixtures than for unexposed groups ${ }^{1,2,4)}$. These studies have suggested an additive effect of co-exposure to noise and organic solvents on the auditory system ${ }^{2-4}$.

Workers co-exposed to noise, N,N-dimethylformamide (DMF) and toluene exist in the synthetic leather manufacturing industries, and DMF is a widely used solvent in such workplaces, because of its excellent miscibility with water and organic solvents, such as toluene, methyl ethyl ketone and ethyl acetate ${ }^{5-7)}$. However, the joint effect of exposure to noise and a mixture of organic solvents on the cardiovascular system is not clear. Because independent exposure to noise, N,Ndimethylformamide (DMF) or toluene is reported to be associated with cardiovascular effects, it is of great interest to investigate their combined effect on hypertension. Many industry-based studies have found that long-term exposure to occupational noise is 
associated with myocardial infarction, coronary heart disease and hypertension ${ }^{8-15}$. One animal study reported that dogs exposed to DMF administered intravenously at a dose of $0.5 \mathrm{~g} / \mathrm{kg}$ showed a myocardial contractile force ${ }^{16)}$. In an experimental study, Mørck and his colleagues found a significant increase of systolic blood pressure (SBP) in printing workers exposed to toluene ${ }^{17)}$. Additionally, a multi-center study showed that long-term exposure (more than $20 \mathrm{yr}$ ) to toluene ranging from 0.4 $216 \mathrm{ppm}$ (median, $24.6 \mathrm{ppm}$ ) increased SBP in printing workers $^{18)}$.

One experimental study reported the combined effect of noise and DMF on disturbances in the metabolic and energy processes of the heart muscle ${ }^{19)}$, but the rat subjects were limited to intermittent ( 2 and $4 \mathrm{~h}$ ) exposure to noise levels above $85 \mathrm{dBA}$ and high doses of DMF exposure ( 1.00 and $5.00 \mathrm{ml} / \mathrm{kg}, 5$ days in a week). The purposes of the present study were to investigate the effects of exposure to noise, a mixture of organic solvents (DMF and toluene) and their interaction on hypertension, and to determine the extent of their joint effect on hypertension in synthetic leather workers.

\section{Subjects and Methods}

\section{Subjects}

The cross-sectional study presented here was conducted in a synthetic leather manufacturing plant with 65 employees during 2005-2006. We recruited 59 volunteers from this plant (response rate, $90.8 \%$ ) as study subjects. These participants included 6 workers engaged in product sampling tests, 8 workers engaged in non-woven fabric manufacturing, 8 workers engaged in wet processes, 10 workers engaged in dry processes, 6 workers engaged in extra processing development (such as printing, pressing, surface arrangement, and inspection), 3 workers in charge of DMF waste recycling, and 18 office workers. The present study was reviewed and approved by the Institutional Review Board of China Medical University Hospital before its execution, and written informed consent was obtained from each participating subject.

\section{Blood pressures measurements and hypertension}

All subjects fasted overnight before blood sampling and blood pressure measurements. After 10 min of sitting, the blood pressure was measured twice by a trained nurse using an automated sphygmomanometer (Ostar Model P2, Ostar Meditech Corp., Taipei, Taiwan). The mean value of two blood pressure measurements was used for the present study. We defined hypertensive subjects as those who reported that their doctors had diagnosed hypertension or those who had a mean value of resting systolic blood pressure $(\mathrm{SBP}) \geq 140 \mathrm{mmHg}$ or a mean value of resting diastolic blood pressure $\geq 90 \mathrm{mmHg}$. Individual height, body weight and total cholesterol level were also measured for all subjects. Body mass index
(BMI) was calculated as body weight $(\mathrm{kg})$ divided by the square of the height $\left(\mathrm{m}^{2}\right)$.

We also used a questionnaire to collect information related to potential confounders during the studying periods. These factors included individuals' age, employment duration, working activity, regular exercise, habits of cigarette smoking, alcohol drinking, tea consumption, coffee consumption, family disease history and the use of personal protective equipment (PPE). Working activity was categorized into high and low levels based on a score system that counted each subject's time of sitting, walking, and lifting heavy objects during working periods, and the distance walked between the worksite and home ${ }^{20)}$. The use of PPE included the percentage of time PPE was worn and the types used (i.e. earplugs/earmuffs, gloves or respirators) at work.

\section{Exposure assessment and group classification}

We measured personal noise exposure continuously by using a personal noise dosimeter (Logging Noise Dose Meter Type 4443, Brüel \& Kjær, Nærum, Denmark), which can report 5-min continuous equivalent sound level (Leq) at an exchange rate of $3 \mathrm{~A}$-weighted decibels (dBA) and the time-weighted average (TWA) noise doses. A range of 50-120 dBA was used to measure all subjects' noise exposure. Each subject carried a Logging Noise Dose Meter to determine personal noise exposure with per 5-min readings during the working period (08:00 a.m.-06:00 p.m.). Individual average noise exposure at work was used to categorize noise exposure.

Personal airborne sampling was conducted by using the U.S.A. Occupational Safety and Health Administration (OSHA) method no. 66 $6^{21}$. An 8-h timeweighted average sample was collected around each subject's breathing zone by using a personal pump (model LFS-113D, Gillian Instrument Corporation, Clearwater, FL) with a flow rate of 50-100 $\mathrm{ml} / \mathrm{min}$. A charcoal tube (cat. No. 226-01; SKC, Eighty Four, PA) was used as sampling media to collect DMF and toluene solvents. We used a Perkin-Elmer autosystem XL gas chromatograph equipped with a flame ionization detector (Perkin-Elmer Co., Norwalk, CT) and a fused silica WCOT DB-WAX $(30 \mathrm{~m} \times 0.25 \mathrm{~mm}$ ID, $0.25 \mu \mathrm{m}$ film thickness) separation column (J \& W Scientific, Folsom, CA) to analyze airborne samples. The details of sample storage, pretreatment, and analyses were described in a previous study ${ }^{7)}$.

In order to examine the co-exposure to DMF and toluene in synthetic leather workers, we assumed an additive effect for these two solvents and calculated the hazard index for mixed solvents in the air using the following formula ${ }^{22)}$ :

Hazard index $(\mathrm{HI})$ of mixture $=\mathrm{C}_{1} / \mathrm{T}_{1}+\mathrm{C}_{2} / \mathrm{T}_{2}$ where $\mathrm{C}_{1}$ and $\mathrm{C}_{2}$ represent the ambient concentrations of DMF and toluene, and $\mathrm{T}_{1}$ and $\mathrm{T}_{2}$ represent the time- 
weighted average threshold limit values of DMF (10 ppm) and toluene (20 ppm), respectively.

According to the personal measurements of noise, DMF and toluene, we classified the 59 study subjects into four different groups: 18 workers co-exposed to noise, DMF and toluene ( $\geq 80 \mathrm{dBA}$ and a hazard index of mixtures $\geq 0.1$; group $1, \mathrm{G} 1$ ); 9 workers with noise exposure only ( $\geq 80 \mathrm{dBA}$ and a hazard index of mixtures $<0.1$; group 2, G2); 15 workers exposed to DMF and toluene ( $<80 \mathrm{dBA}$ and a hazard index of mixtures $\geq 0.1$; group 3, G3) and 17 others with low noise exposure and low DMF and toluene exposure $(<80 \mathrm{dBA}$ and a hazard index of mixtures $<0.1$; group $4, \mathrm{G} 4$ ). We chose $80 \mathrm{dBA}$ as the cut-off value between high and low noise exposure because occupational exposure to $80 \mathrm{dBA}$ over $5 \mathrm{yr}$ was associated with hypertension ${ }^{10,12)}$.

\section{Statistical analysis}

We performed univariate comparisons between the three high-exposure groups (G1-G3) and the lowexposure group (G4) using the Mann-Whitney test for continuous variables and Fisher's exact test for dichotomous variables. We used multivariate logistic regression and calculated odds ratios (ORs) and 95\% confidence intervals (CIs) to compare between-group differences of hypertension controlling for potential confounders. In order to assess the biological interaction of exposure to noise and organic solvents on the risk of hypertension, we defined the relative risk (RR) of hypertension for G1 workers, G2 workers and G3 workers compared to low-exposure workers as $\mathrm{RR}_{11}, \mathrm{RR}_{10}$ and $\mathrm{RR}_{01}$, respectively. Because the relative risk can be replaced with the odds ratio used in the additive model ${ }^{23)}$, the expected $\mathrm{OR}_{11}$ would be the value of $\mathrm{OR}_{10}+\mathrm{OR}_{01}$ $1^{24)}$. Additionally, the Rothman synergy index ${ }^{25)}$ and its 95\% CI was calculated to investigate the joint effect of the two factors. The SAS standard package for Windows version 9.1 (SAS Institute Incorporation, Cary, North Carolina, USA) was used for statistical analyses and a significance level of 0.05 was chosen for all tests in the present study.

\section{Results}

Table 1 summarizes the demographic characteristics and potential risk factors of the four different groups of 59 study subjects. Workers co-exposed to noise, DMF and toluene (G1) and workers exposed to DMF and toluene (G3) had significantly higher means of body mass index than those with low noise, DMF and toluene exposures (G4). Only G1 workers had a significantly high male population and prevalence rate of smoking compared to G4 workers. There were no significant differences between the high-exposure groups (G1-G3) and the low-exposure group (G4) for age, employment duration, total cholesterol level, working activity, alcohol drinking, coffee consumption, tea consumption, regular exercise and family history of hypertension $(p>0.05)$. Only one G1 worker used earplugs/earmuffs and a respirator and five $\mathrm{G} 2$ workers wore earplugs/earmuffs throughout the working period.

Table 2 summarizes the personal exposure levels to noise, DMF and toluene of the four groups during the working period. All of the high-exposure groups had significantly higher means of noise levels (G1: $82.22 \pm$ $2.70 \mathrm{dBA} ; \mathrm{G} 2: 84.13 \pm 2.30 \mathrm{dBA} ; \mathrm{G} 3: 75.20 \pm 1.84 \mathrm{dBA})$ than the low-exposure group (G4: $72.81 \pm 2.16 \mathrm{dBA})$. Both G1 and G3 workers had significantly higher mean values of DMF levels $(4.98 \pm 1.92 \mathrm{ppm}$ and $2.49 \pm 1.80$ ppm) than $\mathrm{G} 4$ workers $(0.41 \pm 0.05 \mathrm{ppm})$. There were significant increases of toluene exposure among G1 and G3 workers $(1.61 \pm 1.60 \mathrm{ppm}$ and $3.30 \pm 2.13 \mathrm{ppm})$, but a significant decrease among G2 workers $(0.09 \pm 0.03$ ppm), compared to G4 workers $(0.12 \pm 0.01 \mathrm{ppm})$. Accordingly, G1 and G3 workers had significantly higher average hazard indices of mixtures in co-exposure to DMF and toluene (G1: $0.53 \pm 0.20 ; \mathrm{G} 3: 0.32 \pm 0.18)$ than that of $\mathrm{G} 4$ workers $(0.04 \pm 0.01)$.

Figure 1 presents the correlations of resting SBP and DBP with the noise exposure (a) and the mixed hazard index (b) for all subjects. We found that both resting SBP and DBP tended to rise with the increasing values of noise exposure and mixed hazard index, although the correlation coefficients were not significant $\left(R^{2}<0.5\right)$. Additionally, resting SBP had a better correlation with both noise and mixture of organic solvents exposure than resting DBP.

Table 3 shows the prevalence of hypertension and age and sex-adjusted risks by group. Both G1 and G3 workers had significantly higher mean values of resting SBP than G4 workers, but the result for G2 workers was not significant ( $p=0.064)$. Only G1 workers had a statistically higher mean value of resting DBP than G4 workers. The prevalence of hypertension was much greater in the coexposure group than that in the solvent-exposure group, the noise-exposure group and the low-exposure group. Compared with G4 workers, the age and sex-adjusted OR for hypertension was found to be highest for G1 workers, followed by G2 and G3 workers.

The associations between different groups and hypertensive risks are summarized in Table 4. Multivariate logistic regression analysis showed that coexposure to noise, DMF and toluene was significantly associated with hypertension after controlling for gender, age, BMI, smoking habits, alcohol consumption, regular exercise, and family history of hypertension. Workers co-exposed to occupational noise of $82.22 \pm 2.70 \mathrm{dBA}$ and a mixed HI of $0.53 \pm 0.20$ had a 13.5 -fold risk of hypertension compared to workers with an occupational noise exposure of $72.81 \pm 2.16 \mathrm{dBA}$ and a mixed $\mathrm{HI}$ of $0.04 \pm 0.01$. We also found that noise-exposure workers 
Table 1. Demographic characteristics and risk factors of hypertension of the four study groups

\begin{tabular}{|c|c|c|c|c|}
\hline \multirow[t]{2}{*}{ Characteristics } & \multicolumn{3}{|c|}{ High-exposure groups } & \multirow[t]{2}{*}{ Low-exposure group } \\
\hline & Co-exposure & Noise exposure & Solvent exposure & \\
\hline Subjects (no.) & 18 & 9 & 15 & 17 \\
\hline \multicolumn{5}{|l|}{ Gender a } \\
\hline Male $(\%)$ & $17(94.4 \%)^{*}$ & $7(77.8 \%)$ & $13(86.7 \%)$ & $10(58.8 \%)$ \\
\hline \multicolumn{5}{|l|}{ Age $(y r)^{b}$} \\
\hline Mean (SD) & $40.3 \pm 5.8$ & $34.6 \pm 7.7$ & $41.6 \pm 9.1$ & $37.6 \pm 7.5$ \\
\hline \multicolumn{5}{|c|}{ Employment duration (yr) ${ }^{b}$} \\
\hline Mean (SD) & $7.9 \pm 0.5$ & $7.4 \pm 1.3$ & $7.5 \pm 1.9$ & $7.6 \pm 1.5$ \\
\hline \multicolumn{5}{|c|}{ Body Mass Index $\left(\mathrm{kg} / \mathrm{m}^{2}\right)^{\mathrm{b}}$} \\
\hline Mean (SD) & $25.7 \pm 3.8 *$ & $23.0 \pm 3.0$ & $25.6 \pm 3.7 *$ & $22.1 \pm 2.9$ \\
\hline \multicolumn{5}{|c|}{ Total cholesterol $(\mathrm{mg} / \mathrm{d} l)^{\mathrm{b}}$} \\
\hline Mean (SD) & $213.9 \pm 32.1$ & $193.4 \pm 38.4$ & $191.4 \pm 32.3$ & $207.2 \pm 46.3$ \\
\hline \multicolumn{5}{|c|}{ Working activity a } \\
\hline High $(\%)$ & $7(38.9 \%)$ & $5(55.6 \%)$ & $6(40.0 \%)$ & $3(17.7 \%)$ \\
\hline Low $(\%)$ & $11(61.1 \%)$ & $4(44.4 \%)$ & $9(60.0 \%)$ & $14(82.3 \%)$ \\
\hline \multicolumn{5}{|l|}{ Smoking a } \\
\hline Yes $(\%)$ & $12(66.7 \%) *$ & $3(33.3 \%)$ & $5(33.3 \%)$ & $3(17.7 \%)$ \\
\hline \multicolumn{5}{|c|}{ Coffee consumption a } \\
\hline Yes $(\%)$ & $2(11.1 \%)$ & $3(33.3 \%)$ & $3(20.0 \%)$ & $6(35.3 \%)$ \\
\hline \multicolumn{5}{|c|}{ Tea consumption a } \\
\hline Yes $(\%)$ & $7(38.9 \%)$ & $6(66.7 \%)$ & $5(33.3 \%)$ & $11(64.7 \%)$ \\
\hline \multicolumn{5}{|c|}{ Alcohol drinking a } \\
\hline Yes $(\%)$ & $2(11.1 \%)$ & $0(0.0 \%)$ & $1(6.7 \%)$ & $1(5.9 \%)$ \\
\hline \multicolumn{5}{|c|}{ Regular exercise a } \\
\hline Yes $(\%)$ & $4(22.2 \%)$ & $1(11.1 \%)$ & $3(20.0 \%)$ & $3(17.7 \%)$ \\
\hline \multicolumn{5}{|c|}{ Family history of hypertension a } \\
\hline Yes $(\%)$ & $6(33.3 \%)$ & $2(22.2 \%)$ & $3(20.0 \%)$ & $2(11.8 \%)$ \\
\hline \multicolumn{5}{|c|}{ The use of personal protective equipment at work } \\
\hline Yes $(\%)$ & $1(5.6 \%)$ & $5(55.6 \%)$ & $0(0.0 \%)$ & $0(0.0 \%)$ \\
\hline
\end{tabular}

a Fisher's exact test of the difference between the 3 high-exposure groups and the low-exposure group; b Mann-Whitney test of the difference between the 3 high-exposure groups and the low-exposure group. $* p<0.05$.

Table 2. Mean \pm SD of noise, DMF, and toluene for the four study groups

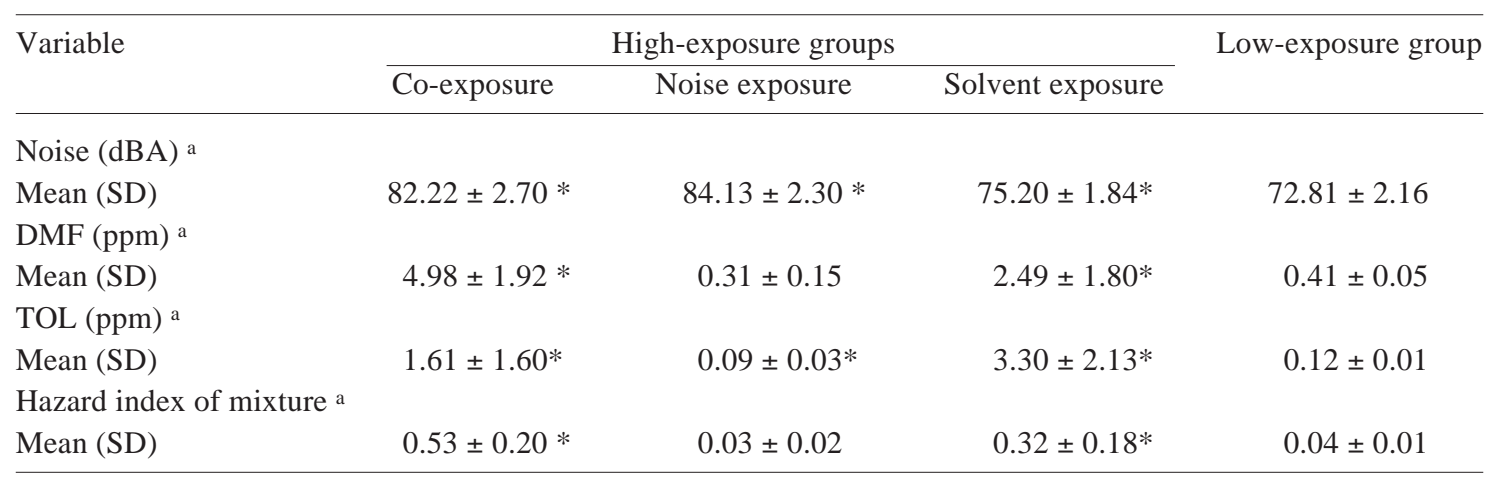

$\mathrm{SD}=$ standard deviation; $\mathrm{DMF}=\mathrm{N}, \mathrm{N}$-dimethylformamide; $\mathrm{dBA}=\mathrm{A}$-weighted decibel. a Mann-Whitney test of the difference between the 3 high-exposure groups and the low-exposure group. ${ }^{*} p<0.05$. 


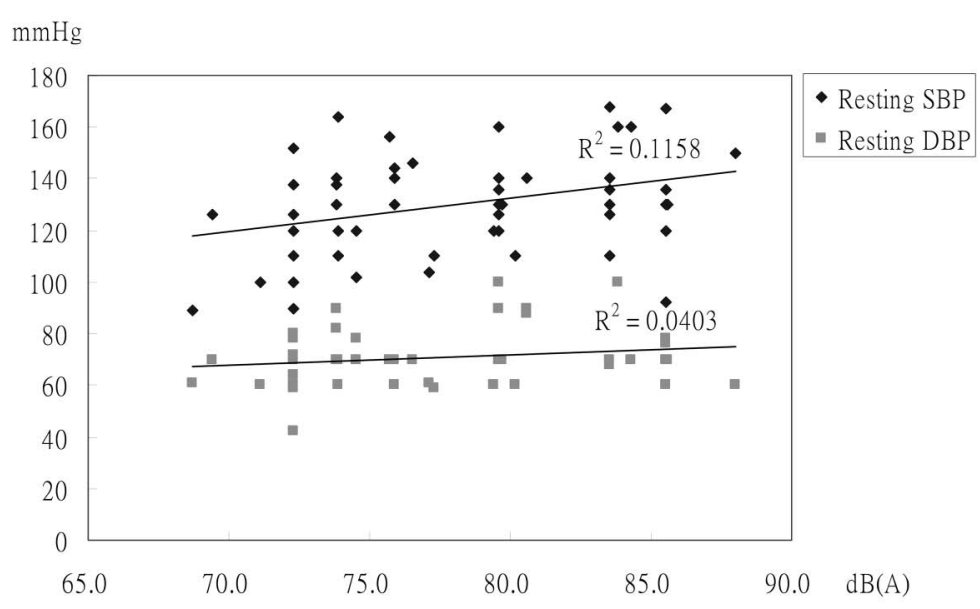

(a)

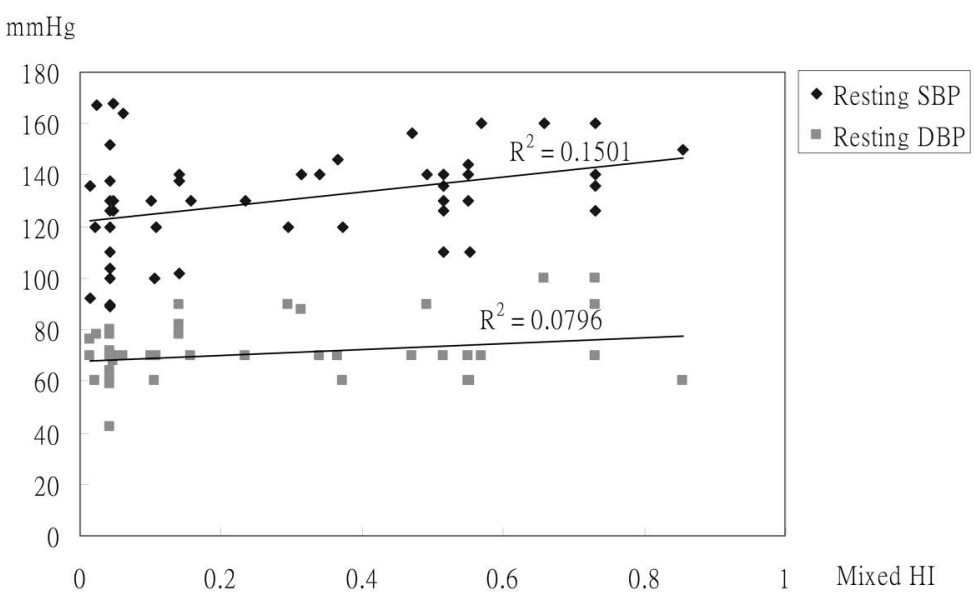

(b)

Fig. 1. Correlations of resting systolic blood pressure (SBP) and diastolic blood pressure (DBP) with (a) noise levels and (b) mixed hazard indices (HIs) for all study subjects.

$(p<0.05)$ and solvent-exposure workers $(p=0.057)$ respectively had 9.1 and 7.9 times the hypertensive risk of low-exposure workers.

Compared with G4 workers, the observed OR for hypertensive risk for G1 workers (13.5) was lower than the expected value of an additive model (i.e. $9.1+7.9-$ $1=16.0$ ). Additionally, the Rothman synergy index was $0.83(95 \% \mathrm{CI}=0.21-3.35)$ in the additive scale.

\section{Discussion}

The present study shows that simultaneous exposure to noise and a mixture of organic solvents might have no strong additive effect on the risk of hypertension. Exposure to either noise or a mixture of organic solvents is associated with an increased prevalence rate of hypertension. Workers exposed to a noise level above $80 \mathrm{dBA}$, and those co-exposed to a mixed HI of DMF and toluene exceeding 0.1 , respectively had 9.1-fold and 7.9-fold higher risk of hypertension than workers with low exposures. Workers co-exposed to a noise level above $80 \mathrm{dBA}$ and a mixed HI of DMF and toluene exceeding 0.1 also showed a significantly increased risk of hypertension $(\mathrm{OR}=13.5)$ compared to workers with low exposures. However, workers simultaneously exposed to noise and organic solvents showed no significantly greater risk of hypertension than those exposed to noise only or co-exposed to DMF and toluene in the present study. The Rothman synergy index was less than one in the present study, indicating a subadditive, not super-additive, effect of co-exposure to 
Table 3. Prevalence of hypertension and age and sex-adjusted ORs (95\% CIs) by study group

\begin{tabular}{lcccrr}
\hline Groups & No. & $\begin{array}{c}\text { Resting SBP } \\
\text { Mean } \pm \mathrm{SD}(\mathrm{mmHg}){ }^{\text {a }}\end{array}$ & $\begin{array}{c}\text { Resting DBP } \\
\text { Mean } \pm \mathrm{SD}(\mathrm{mmHg})^{\text {a }}\end{array}$ & $\begin{array}{c}\text { Hypertension } \\
\text { No. }(\%)\end{array}$ & OR (95\% CI) \\
\hline Low-exposure & 17 & $118.8 \pm 19.6$ & $65.1 \pm 8.9$ & $2(11.8)$ & 1.0 \\
Solvent-exposure & 15 & $131.7 \pm 15.7^{* *}$ & $70.7 \pm 8.0$ & $7(46.7)$ & $7.0(1.0-48.4)$ \\
Noise-exposure & 9 & $134.1 \pm 24.7^{*}$ & $70.3 \pm 5.4$ & $4(44.4)$ & $7.9(1.0-64.0)$ \\
Co-exposure & 18 & $136.1 \pm 15.5^{* *}$ & $76.9 \pm 13.0^{* *}$ & $10(55.6)$ & $11.1(1.6-76.2)$ \\
\hline
\end{tabular}

$\mathrm{SBP}=$ systolic blood pressure; $\mathrm{DBP}=$ diastolic blood pressure; $\mathrm{SD}=$ standard deviation; $\mathrm{OR}=\mathrm{odds}$ ratio; $95 \% \mathrm{CI}=95 \%$ confidence interval. a Mann-Whitney test of the difference between the 3 high-exposure groups and the low-exposure group. $* p<0.10 ; * * p<0.05$.

Table 4. Associations between noise and solvent exposure and the risk of hypertension by multivariate logistic regression

\begin{tabular}{lrcrcc}
\hline Variables & No. & $\begin{array}{c}\text { Hypertension No. } \\
(\%)\end{array}$ & $\begin{array}{c}\text { Logistic Regression } \\
\text { Coefficient }\end{array}$ & $\begin{array}{c}\text { Standard } \\
\text { error }\end{array}$ & OR (95\% CI) \\
\hline Solvent exposure vs. low exposure & $15 / 17$ & $7(46.7) / 2(11.8)$ & 2.067 & 1.085 & $7.9(0.9-66.3)^{*}$ \\
Noise exposure vs. low exposure & $9 / 17$ & $4(44.4) / 2(11.8)$ & 2.207 & 1.116 & $9.1(1.0-81.1)^{* *}$ \\
Co-exposure vs. low exposure & $18 / 17$ & $10(55.6) / 2(11.8)$ & 2.600 & 1.107 & $13.5(1.5-117.8)^{* *}$ \\
Gender (male vs. female) & $47 / 12$ & $19(40.4) / 4(33.3)$ & -0.245 & 0.934 & $0.8(0.1-4.9)$ \\
Age $(\geq 40$ yr vs. $<40$ yr) & $28 / 31$ & $12(42.9) / 11(35.5)$ & 0.317 & 0.651 & $1.4(0.4-4.9)$ \\
BMI $\left(\geq 24 \mathrm{~kg} / \mathrm{m}^{2}\right.$ vs. $\left.<24 \mathrm{~kg} / \mathrm{m}^{2}\right)$ & $29 / 30$ & $13(44.8) / 10(33.3)$ & -0.004 & 0.738 & $1.0(0.2-4.2)$ \\
Smoking (yes vs. no) & $23 / 36$ & $9(39.1) / 14(38.9)$ & -0.739 & 0.768 & $0.5(0.1-2.2)$ \\
Alcohol consumption (yes vs. no) & $4 / 55$ & $2(50.0) / 21(38.2)$ & 0.984 & 1.306 & $2.7(0.2-34.6)$ \\
Regular exercise $($ yes vs. no) & $11 / 48$ & $6(54.6) / 17(35.4)$ & 0.769 & 0.808 & $2.2(0.4-10.5)$ \\
Family history of hypertension (yes vs. no) & $13 / 46$ & $8(61.5) / 15(32.6)$ & 0.927 & 0.445 & $2.5(0.6-10.9)$ \\
\hline
\end{tabular}

$\mathrm{OR}=$ odds ratio; $95 \% \mathrm{CI}=95 \%$ confidence interval. $* p<0.10 ; * * p<0.05$.

noise, DMF and toluene on the risk of hypertension.

One possible reason for the sub-additive effect of coexposure to noise and organic solvents on hypertension might be the insufficient intensity of exposure. A prolonged exposure to both noise and organic solvents would possibly promote atherosclerosis by direct toxic effects on the arterial walls, developing hypertension only at high levels of exposure ${ }^{26,27)}$. Morata et al..$^{2}$ reported a super-additive effect on hearing loss among workers coexposed to noise (above $85 \mathrm{dBA}$ ) and toluene (10-70 $\mathrm{ppm}$ ) that was much higher than that of the present study. Another possibility might be that exposure levels of noise and toluene of G1 workers were lower than those of G2 and G3 workers. G1 workers were co-exposed to a noise level of $82.22 \pm 2.70 \mathrm{dBA}$ and a toluene level of $1.61 \pm$ $1.60 \mathrm{ppm}$ compared to $\mathrm{G} 2$ workers who were exposed to a noise level of $84.13 \pm 2.30 \mathrm{dBA}$, and G3 workers who were exposed to a toluene level of $3.30 \pm 2.13 \mathrm{ppm}$.

Our findings suggest that exposure to noise and/or a mixture of DMF and toluene was associated with an elevation of blood pressure that is in agreement with previous reports. Fogari et al. ${ }^{12)}$ found that occupational exposure to noise levels exceeding $80 \mathrm{dBA}$ lead to an elevation of $1.0 \mathrm{mmHg}$ in resting SBP among metallurgic workers aged from 31 to $40 \mathrm{yr}$. We observed a higher average increase of $15.3 \mathrm{mmHg}$ in resting SBP among synthetic leather workers aged $34.6 \pm 7.7 \mathrm{yr}$ at a noise level of $84.13 \pm 2.30 \mathrm{dBA}$ compared to low-exposure workers. The higher increase in SBP found in the present study might be due to the greater between-group difference in noise exposure ( $84 \mathrm{dBA}$ vs. $72 \mathrm{dBA}$ ), compared to Fogari et al. ( $\geq 80 \mathrm{dBA}$ vs. $<80 \mathrm{dBA})$. An animal study reported that dogs given a single intravenous injection of DMF at a dose of $0.5 \mathrm{~g} / \mathrm{kg}$ showed an average increase of $17 \mathrm{mmHg}$ in systolic arterial pressure after 10 min $^{16)}$. Mørck et al. ${ }^{17)}$ found that toluene exposure was significantly and positively correlated with SBP among male workers with a median employment duration of $20 \mathrm{yr}$. Gericke et al. ${ }^{18)}$ reported that printing workers or their helpers exposed to toluene at a median concentration of $24.57 \mathrm{ppm}$ for more than $20 \mathrm{yr}$ had a resting SBP above $175 \mathrm{mmHg}$. We found workers coexposed to DMF at $2.49 \pm 1.80 \mathrm{ppm}$ and toluene at 3.30 $\pm 2.13 \mathrm{ppm}$ for more than $7 \mathrm{yr}$ had a lower average 
increase of $12.9 \mathrm{mmHg}$ in resting $\mathrm{SBP}$ than low-exposure workers. The lower increase in SBP in the present study might have arisen from the lower level of solvent exposure and the shorter exposure duration compared to previous studies. We observed significantly higher mean elevation values of $17.3 \mathrm{mmHg}$ in $\mathrm{SBP}$ and $11.8 \mathrm{mmHg}$ in DBP among workers co-exposed to noise levels of $82.22 \pm 2.70 \mathrm{dBA}$, a DMF level of $4.98 \pm 1.92 \mathrm{ppm}$ and a toluene level of $1.61 \pm 1.60 \mathrm{ppm}$ compared to lowexposure workers. Our findings are consistent with the toxicological evidence of the combined effect of exposures to higher noise levels (85 and $95 \mathrm{dBA}$ ) and DMF doses $(1.00$ and $5.00 \mathrm{~m} / / \mathrm{kg})$ on the metabolism of the myocardium in rats ${ }^{19}$.

The observed relationships between increased blood pressure and exposure to noise and/or a mixture of organic solvents, even under recommended exposure limits both for noise and a mixture of DMF and toluene, are important issues which require attention for the protection of workers from hypertension. Although there were no interactive effects on blood pressure between exposure to noise and a mixture of organic solvents, we still found increases in resting SBP and DBP respectively by averaging $2.0 \mathrm{mmHg}$ and $6.6 \mathrm{mmHg}$ between $\mathrm{G} 1$ and $\mathrm{G} 2$ workers, and $4.40 \mathrm{mmHg}$ and $6.2 \mathrm{mmHg}$ between G1 and G3 workers. We suggest that synthetic leather workers should use PPE (such as earplugs/earmuffs and a respirator) for noise exposures above $80 \mathrm{dBA}$ and/or a mixed $\mathrm{HI}$ above 0.1 during their working periods.

A strength of this industry-based study is the use of a complete exposure assessment to reduce the discrepancies in measurements between environmental and individual sampling. Additionally, such an approach to exposure assessment prevents information bias arising from the misclassification of exposure groups relying on the use of job title or job category ${ }^{28}$. However, a cross-sectional design may restrict causal inference between occupational exposure and hypertension. Although all of the groups had similar mean lenghts of employment duration, about 7 yr working in the same environment, the unknown status of subjects' health before they were employed means interpretation of the between-group differences in hypertension cannot be solely limited to occupational exposure. Additionally, the small sample size (only 59 subjects) may restrict the ability to make a detailed confounding adjustment for all person-related factors and resulted in wide confidence intervals for the odds ratios in the present study.

Another limitation of the present study is the overestimation of the effects of exposure to noise and/or a mixture of organic solvents on hypertension, because not all potential confounders were considered as covariates in our analyses. Important but uncontrolled risk factors of hypertension among our study subjects include low-density lipoprotein cholesterol, salt in diet and dietary potassium ${ }^{29,30)}$. These unmeasured factors might have contributed to the sustained differences seen between the high-exposure groups and the low-exposure group.

Finally, the present study did not consider skin penetration in evaluating solvent exposure. In addition to pulmonary respiration, both DMF and toluene vapors can also be absorbed through the skin ${ }^{5,7)}$. Because no workers reported wearing gloves throughout the working period, it is possible that we underestimated workers' exposure to mixed solvents from skin contact. Therefore, we recommend that future investigators be aware of this potential bias and consider using a biological marker for measuring solvent exposure during study periods.

Regardless of these limitations, we conclude that there is an association between hypertension and co-exposure to noise and a mixture of organic solvents in synthetic leather workers. Either exposure to noise exceeding 80 $\mathrm{dBA}$ or a mixed hazard index of DMF and toluene above 0.1 may increase the risk of hypertension. Combined exposures to noise, DMF and toluene may have a subadditive interaction on hypertension. Future human studies with a follow-up design and a larger number of subjects are still needed to confirm our findings regarding co-exposure to noise and mixed solvents on the risk of hypertension.

Acknowledgments: We thank the National Science Council, Taiwan (NCS94-2211-E-039-005 and NSC942211-E-039-006) and China Medical University (CMU94-085) for the financial support. We thank all individuals who volunteered to participate in this study and the graduate students who assisted with airborne sampling at the workplace.

The authors declare they have no competing financial interests.

\section{References}

1) Jacobsen P, Hein HO, Suadicani P, Parving A, Gyntelberg F. Mixed solvent exposure and hearing impairment: An epidemiological study of 3,284 menThe Copenhagen male study-. Occup Med (Lond) 1993; 43: 180-4.

2) Morata TC, Dunn DE, Kretschmer LW, Lemasters GK, Keith RW. Effects of occupational exposure to organic solvents and noise on hearing. Scand J Work Environ Health 1993; 19: 245-54.

3) Sliwinska-Kowalska M, Zamyslowska-Szmytke E, Szymczak W, et al. Effects of coexposure to noise and mixture of organic solvents on hearing in dockyard workers. J Occup Environ Med 2004; 46: 30-8.

4) Kim J, Park H, Ha E, Jung T, Paik N, Yang S. Combined effects of noise and mixed solvents exposure on the hearing function among workers in the aviation industry. Ind Health 2005; 43: 567-73.

5) Yang JS, Kim EA, Lee MY, Park IJ, Kang SK. 
Biological monitoring of occupational exposure to $\mathrm{N}$, $\mathrm{N}$-dimethylformamide-The effects of co-exposure to toluene or dermal exposure-. Int Arch Occup Environ Health 2000; 73: 463-70.

6) Chang HY, Shih TS, Guo YL, Tsai CY, Hsu PC. Sperm function in workers exposed to N,Ndimethylformamide in the synthetic leather industry. Fertil Steril 2004; 81: 1589-94.

7) Wang VS, Shih TS, Chang HY, Lai JS, Lin CC. Evaluation of current biological exposure index for occupational N,N-dimethylformamide exposure from synthetic leather workers. J Occup Environ Med 2004; 46: 729-36.

8) Johsson A, Hansson L. Prolonged exposure to a stressful stimulus (noise) as a cause of raised bloodpressure in man. Lancet 1977; 1: 86-7.

9) Fouriaud C, Jacquinet-Salord MC, Degoulet P, et al. Influence of socioprofessional conditions on blood pressure levels and hypertension controlEpidemiologic study of 6,665 subjects in the Paris district-. Am J Epidemiol 1984; 120: 72-86.

10) Verbeek JH, van Dijk FJ, de Vries FF. Non-auditory effects of noise in industry-A field study on industrial noise and blood pressure-. Int Arch Occup Environ Health 1987; 59: 51-4.

11) Zhao YM, Zhang SZ, Selvin S, Spear RC. A dose response relation for noise induced hypertension. $\mathrm{Br} \mathrm{J}$ Ind Med 1991; 48: 179-84.

12) Fogari R, Zoppi A, Vanasia A, Marasi G, Villa G. Occupational noise exposure and blood pressure. J Hypertens 1994; 12: 475-9.

13) Tomei F, Fantini S, Tomao E, Baccolo TP, Rosati MV. Hypertension and chronic exposure to noise. Arch Environ Health 2000; 55: 319-25.

14) Virkkunen H, Kauppinen T, Tenkanen L. Long-term effect of occupational noise on the risk of coronary heart disease. Scand J Work Environ Health 2005; 31 : 291-9.

15) Davies HW, Teschke K, Kennedy SM, Hodgson MR, Hertzman C, Demers PA. Occupational exposure to noise and mortality from acute myocardial infarction. Epidemiology 2005; 16: 25-32.

16) Pham Huu C, Azum-Gelade MC, Nguyen Van B, Nguyen Dat X. Cardiovascular activity of N,Ndimethylformamide. Toxicology 1973; 1: 135-41.

17) Mørck HI, Winkel P, Gyntelberg F. Health effects of toluene exposure. Dan Med Bull 1988; 35: 196-200.
18) Gericke C, Hanke B, Beckmann G, Baltes MN, Kühl KP, Neubert D. Multicenter field trial on possible health effects of toluene-Evaluation of effects after longterm exposure-. Toxicology 2001; 168: 185-209.

19) Ivanovich E, Antov G, Goranova L, Spasovski M, Bainova A, Vasileva Z. Combined effect of some physical and chemical factors. J Hyg Epidemiol Microbiol Immunol 1985; 29: 105-10.

20) Hwang LC, Chen CJ, Tsieng WP. A nested case control study on multiple risk factors for acute fatal cerebrovascular accident and coronary heart disease. Chin J Fam Med 1997; 7: 121-30 (in Taiwan).

21) Occupational Safety and Health Administration (OSHA). Analytical methods Manual, 2nd ed., Method no. 66. Salt Lake City (UT): Analytical Laboratory; 1990.

22) American Conference of Governmental Industrial Hygienists (ACGIH). Adopted Appendix C: Threshold limit values for mixtures. In: 2001 Threshold Limit Values for Chemical Substances and Physical Agents and Biological Exposure Indices. Cincinnati $(\mathrm{OH})$ : ACGIH; 2001. p. 36-7.

23) Greenland S, Rothman KJ. Concepts of interaction. In: Rothman KJ, Greenland S. Modern Epidemiology, 2nd ed. Philadelphia (PA): Lippincott-Raven; 1998. p. 32942.

24) Breslow NE, Storer BE. General relative risk functions for case-control studies. Am J Epidemiol 1985; 122: 149-62.

25) Rothman KJ. The estimation of synergy or antagonism. Am J Epidemiol 1976; 103: 506-11.

26) Kotseva K, Popov T. Study of the cardiovascular effects of occupational exposure to organic solvents. Int Arch Occup Environ Health 1998; 71(Suppl): S87-91.

27) Chang TY, Su TC, Lin SY, Jain RM, Chan CC. Effects of occupational noise exposure on 24-hour ambulatory vascular properties in male workers. Environ Health Perspect 2007; 115: 1660-4.

28) Checkoway H, Pearce N, Kriebel D. Precision and validity in study design. In: Research Method in Occupational Epidemiology, 2nd ed. New York: Oxford University Press; 2004. p. 83-121.

29) Lemne C, Hamsten A, Karpe F, Nilsson-Ehle P, Faire Ude. Dyslipoproteinemic changes in borderline hypertension. Hypertension 1994; 24: 605-10.

30) Beilin LJ, Puddey IB, Burke V. Lifestyle and hypertension. Am J Hypertens 1999; 12: 934-45. 